fournal of Medical Genetics (1970). 7, 83.

\title{
A Female with the 48,XXXX Karyotype
}

\author{
MURIEL I. K. BERKELEY and MICHAEL J. W. FAED
}

From the Medical Research Council, Clinical and Population Cytogenetics Unit, Western General Hospital, Edinburgh 4

Only a few patients with a $48, \mathrm{XXXX}$ karyotype have so far been described in the literature. The patient reported here was identified in a nuclear sexing survey of female patients in a hospital for the mentally defective.

\section{Case Report}

This woman, born on 25 October 1916, was the only child of non-consanguineous parents. At the time of her birth her mother was aged 31 years and her father 26 years.

Pregnancy had been uneventful, no chemotherapy or $x$-rays had been given, and no infections or other illnesses had occurred. The mother had not had any abortions, miscarriages, or stillbirths, and there was no history of congenital abnormalities or mental deficiency in the family.

At birth the baby appeared normal. She walked at 12 months, spoke at 18 months but was said to be 'slow at learning'. During infancy she suffered from epilepsy. She went to school at the age of 10 years and was transferred to a special school at 12 years, but because of behavioural difficulties, emotional instability, and an inability to take any interest, she was excluded after only a few months. She was subsequently cared for at home, where she showed considerable practical ability with domestic work. She had occasional temper tantrums which increased in frequency after the death of her father in 1965. In 1966, at the age of 50 she was admitted to a hospital for the mentally defective.

On examination there were no gross physical abnormalities but her general appearance suggested mental retardation (Fig. 1). Voluntary and emotional movements and responses were slow and lacking in spontaneity, and semi-automatic movements such as blinking and swinging of the arms in walking were impaired. There was no rigidity typical of Parkinsonism and no tremor.

The mouth was endentulous. The head hair was straight and coarse, the neck was short, and there was a moderate dorsal kyphosis.

The abdomen was protuberant due to obesity and there was generalized mild varicosity of both legs.

Pronation and supination of the forearms were limited, more so on the right than the left, but no bony abnormality was observed on $x$-ray of the elbows, forearms, and wrists.

Received 24 October 1969.
The middle and terminal phalanges of both hands appeared abnormally short.

There was an apical cardiac systolic murmur but no confirmatory evidence of heart disease.

Her IQ was found to be too low to register on the W.A.I.S., but she scored at the 5-year level on the Coloured Ravens Progressive Matrices, and at the 7-year level on the Vernon vocabulary test.

An electroencephalogram showed bilateral sharp wave disturbances which would be consistent with underlying epileptic activity and possible focal disturbances in the right temporal region. Apart from the generalized akinesia there were no abnormal neurological signs on clinical examination. The CSF was not examined.

Sexual development. Menarche occurred at 12 years of age and menstruation had been regular and normal until the menopause at 50 years. Breast development was normal, axillary hair was sparse, and pubic hair was normal in amount with a straight upper margin. The clitoris and labia minora were normal but the labia majora were underdeveloped and unpigmented. The vagina and uterus were normal on palpation.

Dermatoglyphs (Professor L. S. Penrose). Total ridge count: 87 (mean for $46, \mathrm{XX}$ females, 127; mean for six other 48,XXXX females, 99); number of small whorls: $4 / 10$ (mean for $46, X X$ females, $2 \cdot 4 / 10$; mean for other $48, \mathrm{XXXX}$ females, 5.8/10); ridge breadth: 0.457 $\mathrm{mm}$. (mean for $46, \mathrm{XX}$ females, $0.514 \mathrm{~mm}$.; mean for other $48, \mathrm{XXXX}$ females, $0.535 \mathrm{~mm}$.). The simplified sole patterns were consistent with the $48, \mathrm{XXXX}$ karyotype.

Colour vision (Ishihara plates). Normal for both mother and daughter.

$\mathbf{X g}^{a}$ blood grouping (Dr. R. Sanger). Positive for both mother and daughter.

Nuclear sex (Dr. N. McLean). Buccal mucosa was examined and gave the results shown in Table I.

TABLE I

SEX CHROMATIN RESULTS FROM BUCCAL SMEAR

\begin{tabular}{l|c|c|c|c}
\hline & \multicolumn{2}{|c|}{$\begin{array}{c}\text { No. of Barr } \\
\text { Bodies }\end{array}$} & Total \\
\hline 1 & 1 & 2 & 3 & \\
\hline No. of nuclei & 96 & 52 & 12 & 200 \\
\hline
\end{tabular}




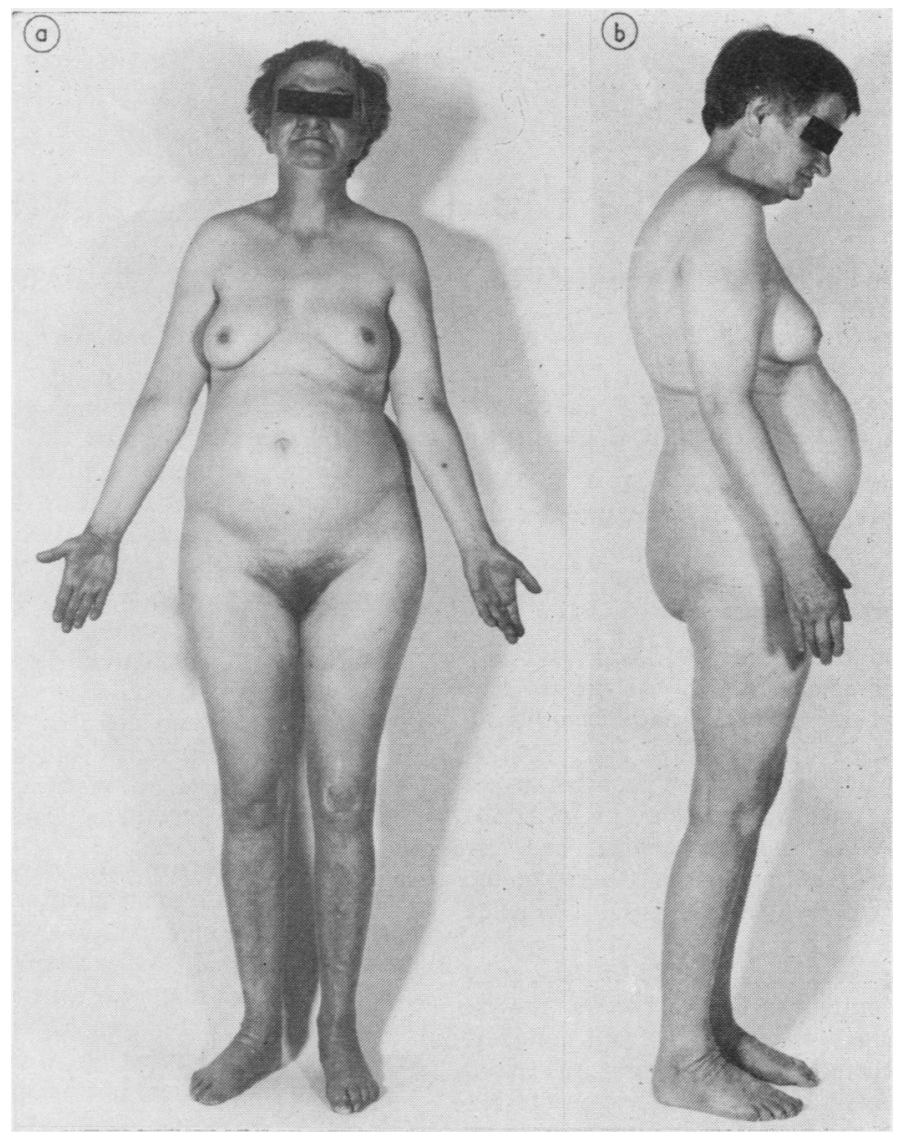

FIG. 1. The patient.

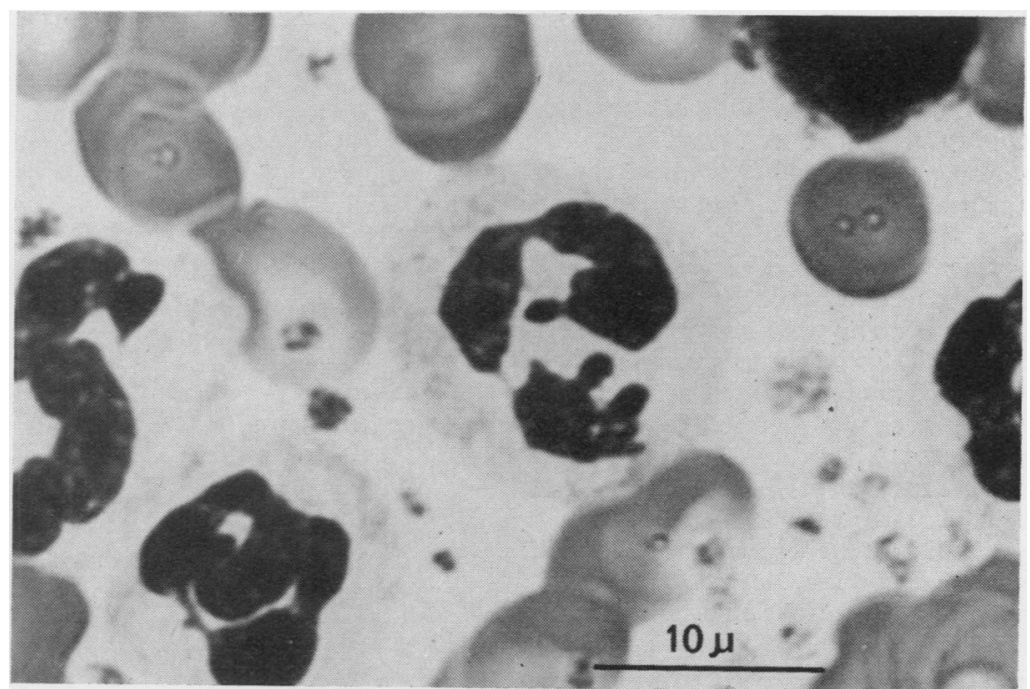

FIG. 2. A neutrophil polymorph leucocyte showing three drumsticks projecting from a multilobed nucleus. 
Blood was examined, and 12 out of 3000 neutrophils had 2 appendages. In a prolonged search for cells with three appendages three such cells were found (Fig. 2).

Chromosome studies. The results of these studies are set out in Table II.

TABLE II

\section{CYTOGENETIC RESULTS}

\begin{tabular}{l|ccccc|c}
\hline & \multicolumn{2}{|c|}{ No. of } & Chromosomes & Total \\
\cline { 2 - 6 } & 45 & 46 & 47 & 48 & 49 & \\
\hline Blood & - & - & 2 & 28 & - & 30 \\
Skin & - & - & 4 & 26 & - & 30 \\
\hline
\end{tabular}

Analysis of the cells with 47 chromosomes showed no evidence of a second cell line. The mother's chromosomes were normal.

Autoradiography. Leucocytes labelled with ${ }^{3} \mathrm{H}$ thymidine at the end of DNA synthesis showed 3 late replicating $\mathrm{C}$ group chromosomes confirming the $48, \mathrm{XXXX}$ chromosome analysis (Fig. 3).

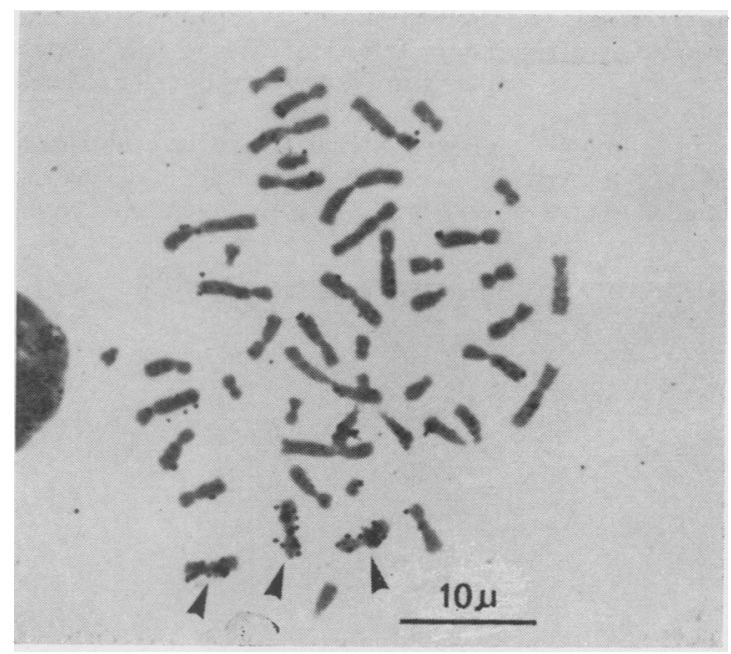

Fig. 3. Cell from blood culture showing terminal labelling of three $\mathrm{C}$ group chromosomes with tritium-labelled thymidine.

\section{Discussion}

Patients with a $48, \mathrm{XXXX}$ karyotype have been described by Carr, Barr, and Plunkett (1961), Davies (1963), Grouchy et al. (1968), Lejeune and Abonyi (1968), and di Cagno and Franceschini (1968). The present case, identified in a hospital for the mentally defective, is the seventh to be reported, and in addition to being mentally subnormal resembles the others in having no gross abnormality of physical or sexual development. Unlike the case reported by Grouchy et al. (1968) she has none of the features of trisomy 21 .

\section{Summary}

An unmarried 52-year-old woman was found to have a $48, \mathrm{XXXX}$ chromosome complement. She was identified during a nuclear sexing survey of female patients in a hospital for the mentally defective. She was severely subnormal, kyphotic, the terminal phalanges were abnormally short, forearm pronation and supination were limited, and the labia majora were underdeveloped. She is the seventh recorded case of a patient with the $48, \mathrm{XXXX}$ karyotype.

We are grateful to Dr. Patricia Jacobs and Dr. W. H. Price for their help and advice with the investigation of this case, and to the technical staff of the M.R.C. Clinical and Population Cytogenetics Research Unit for invaluable assistance. We would also like to thank Dr. T. L. Pilkington and Dr. A. S. Afara for their kind co-operation.

\section{REPERENCES}

Carr, D. H., Barr, M. L., and Plunkett, E. R. (1961). An XXXX sex chromosome complex in two mentally defective females. The Canadian Medical Association fournal, 84, 131-137.

Davies, T. S. (1963). Buccal smear surveys for sex chromatin. British Medical fournal, 1, 1541-1542.

di Cagno, L., and Franceschini, P. (1968). Feeblemindedness and XXXX karyotype. Fournal of Mental Deficiency Research, 12, 226-236.

Grouchy, J. de, Brissaud, H. E., Richardet, J. M., Repéssé, G., Sanger, R., Race, R. R., Salmon, Ch., and Salmon, D. (1968). Syndrome 48,XXXX chez une enfant de six ans. Transmission anormale due groupe Xg. Annales de Génétique, 11, 120-124.

Lejeune, J., and Abonyi, D. (1968). Syndrome 48, XXXX chez une fille de quatorze ans. Annales de Génétique, 11, 117-119. 